\title{
The efficacy of ischemic conditioning in the prevention of gastroesophageal anastomotic complications: a meta-analysis
}

\author{
Ze-Guo Zhuo", Xu Shen", Tie-Niu Song, Zhi-Jie Xu, Gu-Ha Alai, Peng Yao, Yi-Dan Lin \\ Department of Thoracic Surgery, West China Hospital, Sichuan University, Chengdu, China \\ Contributions: (I) Conception and design: YD Lin; (II) Administrative support: YD Lin; (III) Provision of study materials or patients: YD Lin; (IV) \\ Collection and assembly of data: ZG Zhuo, X Shen, TN Song, ZJ Xu, GH Alai, P Yao. (V) Data analysis and interpretation: ZG Zhuo, X Shen, TN \\ Song, ZJ Xu, GH Alai, P Yao; (VI) Manuscript writing: All authors; (VII) Final approval of manuscript: All authors. \\ \#These authors contributed equally to this work. \\ Correspondence to: Yi-Dan Lin. Department of Thoracic Surgery, West China Hospital, Sichuan University, 37 Guoxue Alley, Chengdu, China. \\ Email: linyidan.academy@foxmail.com.
}

\begin{abstract}
Background: The blood supply to the gastric conduit is thought to be the most crucial factor affecting the healing of the gastroesophageal anastomosis. By selective ligation or embolization of gastric vessels, ischemic conditioning (IC) could promote the hypertrophy and neovascularization of the remaining gastric vessels. So that it could help the stomach adapt to the decline of blood supply before esophagectomy. However, the safety and efficacy of the technique still needs to be proved. Several new studies on this topic have been published recently. We conduct this meta-analysis to update the evidence on this topic.

Methods: A logistic searching strategy was designed to find out related publications on four medical databases (PubMed, EMBASE, Medline, and Cochrane Central Register of controlled trials). The included studies were confirmed by reading the title, abstract, or full text. Based on these included studies, the comparison of postoperative outcomes between patients who received IC and those did not was made. After that, the safety and efficacy of IC were assessed.

Results: Fourteen studies were enrolled in the meta-analysis. The pooled analysis showed IC reduced the incidence of anastomotic leakage significantly. And both the embolization and laparoscopic ligation approach were effective. The subgroup analysis indicated the interval between IC and esophagectomy should be over two weeks before the IC worked. The IC also could decrease the anastomotic stricture rate dominantly. What's more, the IC didn't increase the mortality.
\end{abstract}

Conclusions: This meta-analysis proved that ischemic conditioning is a safe intervention that could reduce anastomotic complications effectively. Future randomized controlled clinical trials are needed to provide high-level evidence on this topic.

Keywords: Esophagectomy; ischemic conditioning (IC); anastomotic complication; meta-analysis

Submitted Nov 29, 2019. Accepted for publication May 19, 2020.

doi: 10.21037/apm-19-569

View this article at: http://dx.doi.org/10.21037/apm-19-569

\section{Introduction}

Esophageal cancer is the $6^{\text {th }}$ leading cause of cancer-related deaths worldwide (1). Regardless of the development of surgical technique and perioperative management, the incidence of anastomotic leakage (AL) remains high $(2,3)$. The blood supply to the gastric conduit is thought to be the most crucial factor affecting the healing of the anastomosis $(4,5)$. The right gastroepiploic artery becomes the primary supplier of the conduit after esophagectomy (6). So the blood supply to the proximal end (near the gastric fundus) of the conduit, which is far away from the primary trunk of the right gastroepiploic artery, is weaker than other parts. And the condition would be even worse in patients who undergo 
cervical anastomosis for a higher anastomotic level. A metaanalysis shows that cervical anastomosis has a significantly higher risk of AL than intrathoracic anastomosis (7).

The evidence above makes us believe the improvement of the blood supply to the anastomotic site is the key to decreasing the incidence of AL. The simplest way to improve the blood supply is by bringing down the anastomotic level. However, it is not feasible in the upper esophageal tumors for the concern of a positive surgical margin (8). Some hospitals have started using fluorescence imaging to guide the selection of the anastomotic site $(9,10)$. However, the technique is unable to deal with a globally poor perfusion conduit. The anastomotic site has to be placed in the proximal end of the conduit to achieve a tension-free anastomosis in some cases (11). The ischemic conditioning (IC) of the stomach was proposed over 20 years ago. By ligation or embolization of the gastric vessels, it promotes hypertrophy and neovascularization of the remaining arteries helping the stomach adapt to the decline of blood supply before esophagectomy (12). Pham and his colleagues observed IC produced a $67 \%$ increase of microvessels counts, compared to the controls (12). The animal model conducted by Perry et al. also showed IC could significantly increase neovascularization (13). What's more, they found the degree of inflammation at the healing anastomosis decreased dominantly. These findings indicate IC could provide a better environment supporting the healing of gastroesophageal anastomosis. The metaanalysis conducted by Heger et al. shows the incidence of $\mathrm{AL}$ is $9.6 \%$ and $11.5 \%$ for patients undergo $\mathrm{IC}$, and those do not, respectively (14). The difference doesn't reach a statistical significance. However, the studies they included were published before the year of 2012. Several new studies on this topic have been published in the past few years. So we conduct this meta-analysis to update the evidence on this topic.

This study was carried out according to the Cochrane handbook for systemic reviews of intervention, and the results were reported following the Preferred Reporting Items for Systemic Reviews and Meta-Analyses (PRISMA) reporting checklist. Available at http://dx.doi.org/10.21037/ apm-19-569.

\section{Methods}

We performed a systematic search in the online database of PubMed, Medline, EMBASE, and Cochrane Central
Register of controlled trials on 30th September 2019 to find out potentially relevant publications. The searching strategy consisted of the following terms: (esophagus OR esophageal or oesophagus OR oesophageal OR esophagectomy OR oesophagectomy) AND (gastric conditioning OR ischemic conditioning OR vascular conditioning OR ischaemic conditioning OR embolization OR devascularization OR preconditioning). This is a meta-analysis. It does not involve any ethical or informed consent problems. This article does not contain any studies with human participants performed by any of the authors.

\section{Inclusion and exclusion criteria}

Inclusion criteria: (I) studies enrolled patients undergoing esophagectomy with gastroesophageal anastomosis; (II) studies compared the outcomes between the patients who received IC, and those did not.

Exclusion criteria: (I) following publication types: review, meta-analysis, case report, study protocol, conference abstract, letter, and reply; (II) when duplicate data occurred, only the study with a larger sample size would be included.

\section{Study screening and data extraction}

The first-round screening was done by reading the titles and abstracts of the studies. Most irrelevant studies were excluded in this step. Then, the second-round screening was performed by reading the full texts of the potentially relevant studies. After that, we started to extract relevant data to finally confirm the studies which could be included in the meta-analysis. The following baseline characteristics data of the studies were collected: Name of the first author, publication year, participants, sample size, ischemic conditioning strategy, and anastomosis technique. The incidence of anastomotic complications was used to evaluate the efficacy of ischemic conditioning.

All the work above was accomplished by two authors (Zhuo and Shen) independently and then checked with each other. Disagreements were resolved by discussing it with another author (Lin).

\section{Quality assessment}

The Methodological Index for Non-Randomized Studies (MINORS) (15), which contained eight items, was used to assess the quality of included studies. 


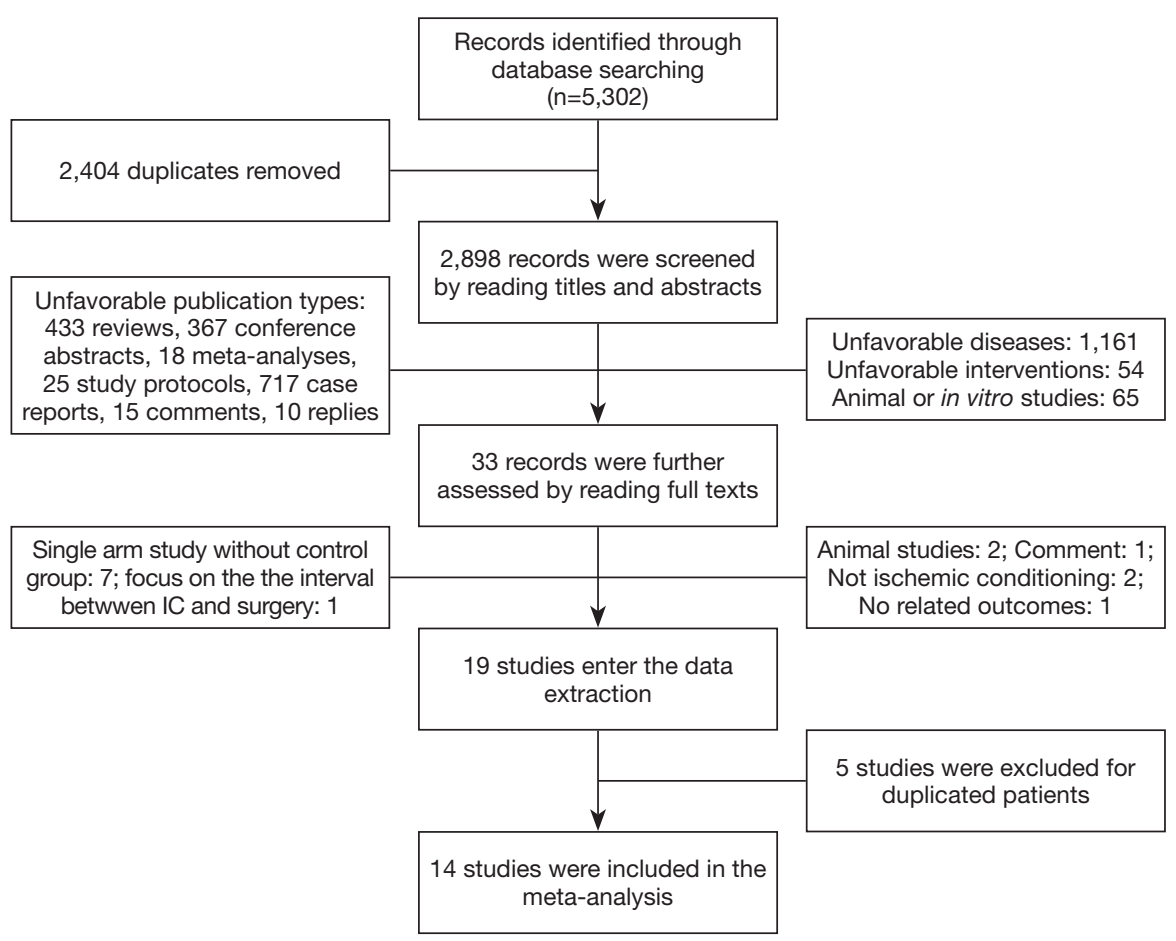

Figure 1 Flow diagram displays the screening procedures of included studies. IC, ischemic conditioning.

\section{Statistical analysis}

The Review Manager Version 5.3 and STATA Version 12.0 software (Stata Corporation, College Station, TX, USA) were used to run the data analysis. The Odds Ratio (OR) was used in the comparison of dichotomous data. The $\mathrm{I}^{2}$ was used as the indicator of heterogeneity. $\mathrm{I}^{2}<25 \%, 25 \% \leq$ $\mathrm{I}^{2}<50 \%$ and $\mathrm{I}^{2} \geq 50 \%$ indicated low, moderate and high heterogeneity. When high heterogeneity was detected, subgroup analysis and meta-regression analysis would be performed to explore the source of heterogeneity. Begg's and Egger's tests were used to detect publication bias. A $P$ value of less than 0.05 was considered to be statistically significant.

\section{Results}

\section{Selection of included studies}

The online database searching identified a total of 5,302 potentially relevant studies. The screening of the included studies was shown in Figure 1. Firstly, two thousand and four duplicated studies were removed. By reading the titles and abstracts, 1,575 unfavorable publication types (reviews, case reports, conference abstracts, meta-analyses, study protocols, replies, and comments), 65 animal or in vitro studies were excluded. Another 1,216 studies which didn't focus on the targeted disease and intervention were excluded as well. Then, 32 potentially relevant studies were carefully checked by reading the full texts. Nineteen of them met the requirements of our study and entered the data extraction step. After the removal of 5 studies with duplicated patients, 14 studies enrolling 1,705 patients were finally included in the meta-analysis.

\section{Baseline characteristics of included studies}

The baseline characteristics of the included studies were shown in Table 1. Four studies (16-19) achieved the IC by embolism of the gastric vessels, while the left ten studies $(5,12,20-27)$ were through the laparoscopic approach. The interval between the IC and esophagectomy varied considerably among the 14 studies ranging from 3 to 205 days. Eleven studies showed the ischemic conditioning (IC) group had a lower incidence of anastomotic leakage (AL) than the no ischemic conditioning (NIC) group, while three studies showed the IC group had a higher rate of AL. 


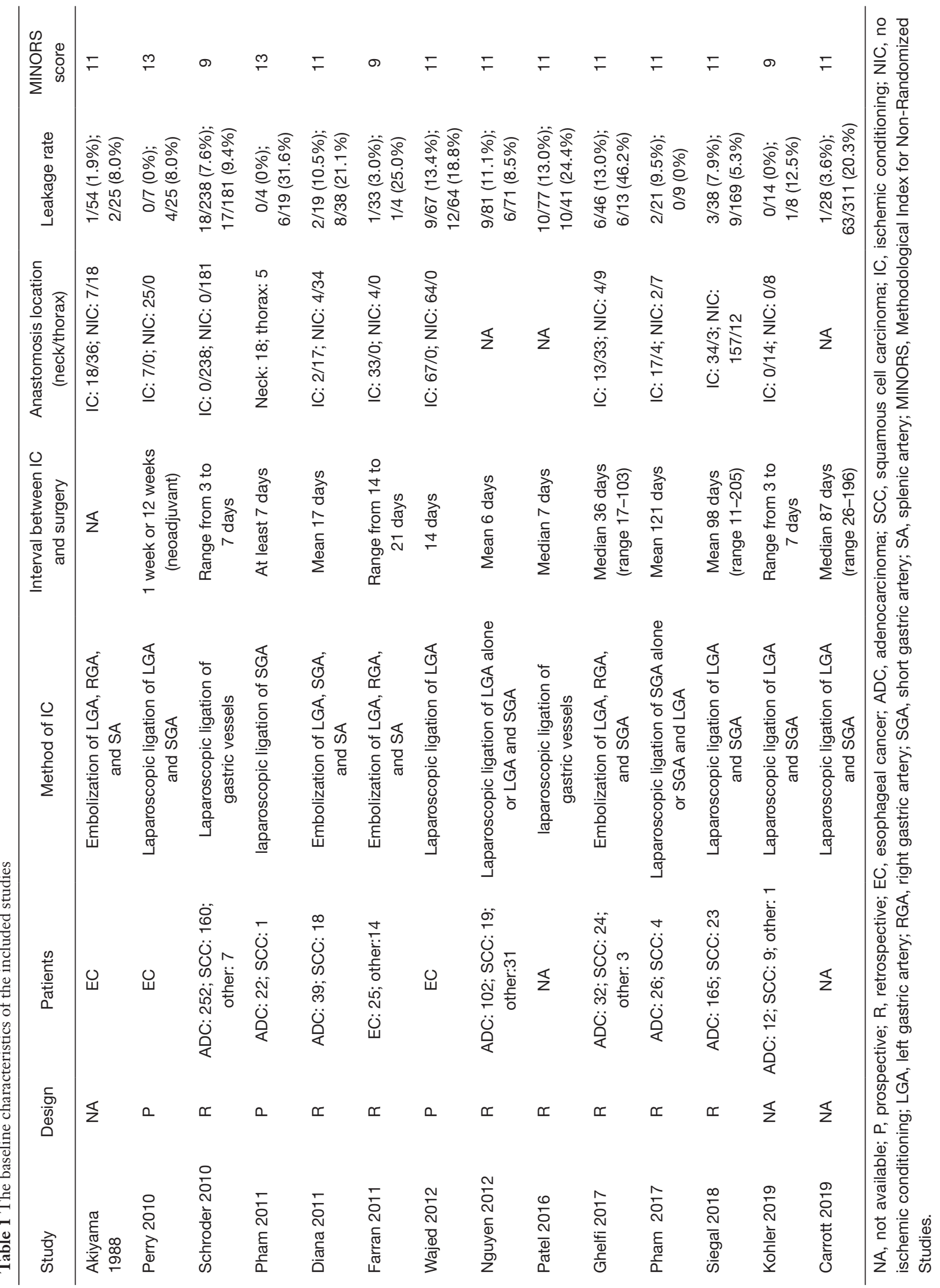




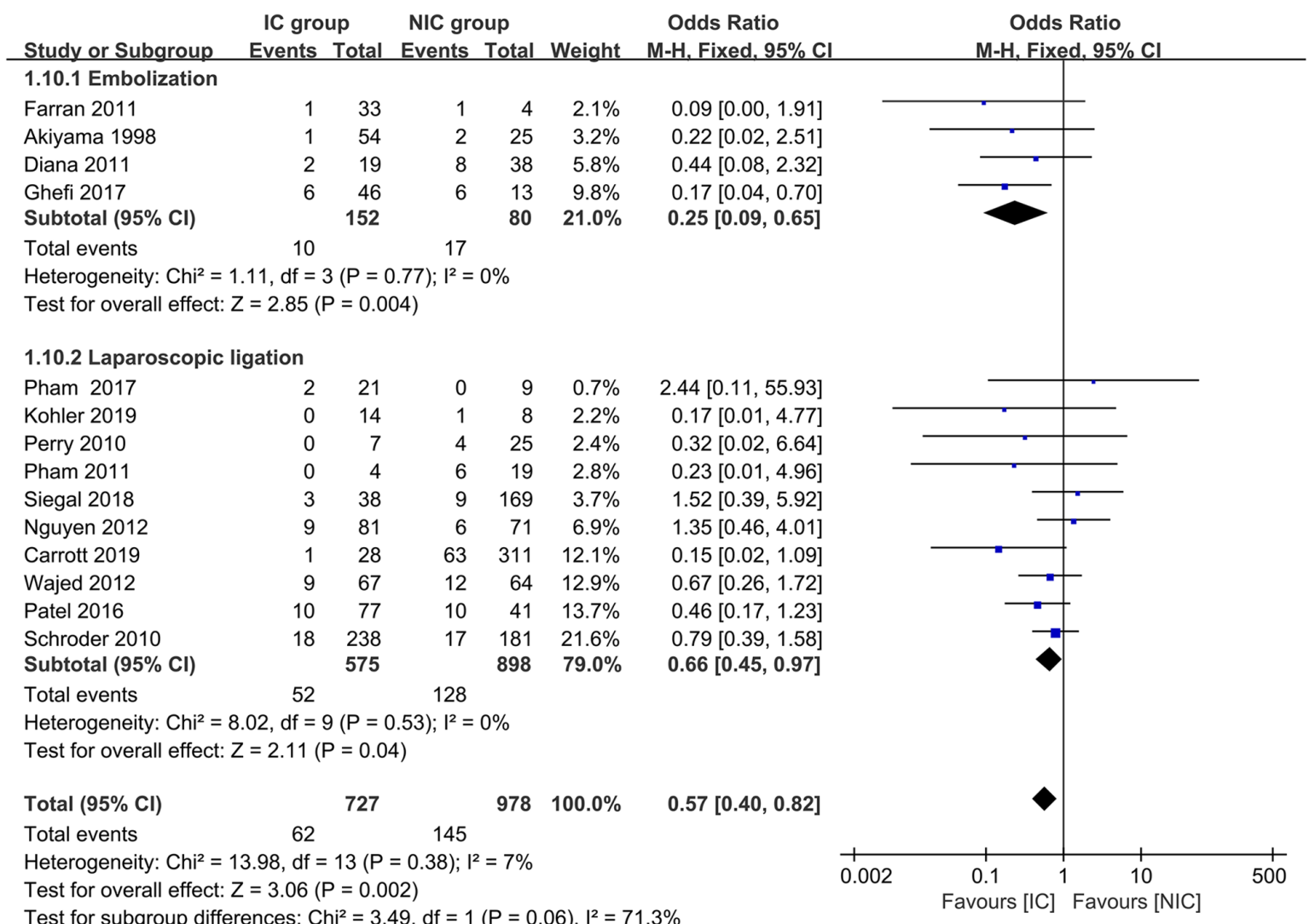

Figure 2 Comparison of anastomotic leakage (AL) rate between ischemic conditioning (IC) group and no ischemic conditioning (NIC) group. The IC group had a lower rate of AL than the NIC group (8.5\% vs. 14.8\%). The difference reached statistically significant (OR $=0.57,95 \%$ CI: $0.40-0.82, \mathrm{P}$ value $=0.002$ ). Both the embolization and laparoscopic ligation approach were efficacy in the reduction of AL.

\section{Comparison of postoperative outcomes}

The data of anastomotic leakage (AL) was available in all 14 studies. The pooled analysis showed the incidence of AL was $8.5 \%$ and $14.8 \%$ for the IC group and NIC group, respectively. The difference reached statistically significant $(\mathrm{OR}=0.57,95 \%$ CI: $0.40-0.82, \mathrm{P}$ value $=0.002$, Figure 2$)$. What's more, both of the embolization and laparoscopic ligation approach were efficacy in the reduction of $\mathrm{AL}$ (Figure 2). A subgroup analysis was performed according to the interval between IC and gastroesophageal anastomosis. It showed the IC was effective in the reduction of $\mathrm{AL}$ when the interval above 2 weeks ( $\mathrm{P}$ value $=0.002$, Figure 3). The incidence of AL was comparable between the IC and NIC group in the one-week subgroup $(7.1 \%$ vs. $9.5 \%$, $\mathrm{P}$ value $=0.36$, Figure 3).

The incidence of anastomotic stricture was available in 9 studies. The overall stricture rate was $12.1 \%$ and $27.9 \%$ in the IC and NIC group, respectively. The meta-analysis showed the IC group had a significantly lower stricture rate than the NIC group (OR $=0.46,95 \%$ CI: $0.29-0.71, \mathrm{P}$ value $=0.0005$, Figure 4 ). On the other hand, the mortality was lower in the IC group, but the difference didn't reach a statistically significant difference $(3.7 \%$ vs. $5.1 \%$, P value $=0.19$, Figure 5).

\section{Heterogeneity and publication bias}

All the analyses above showed low or moderate heterogeneity. The Begg's $(\mathrm{P}$ value $=0.913$, Figure $6 \mathrm{~A}$ ) and Egger's test (P value $=0.544$, Figure $6 B$ ) showed no publication bias.

\section{Discussion}

Anastomotic leakage (AL) and anastomotic stenosis (AS) are the two mainly anastomosis-related complications. The 


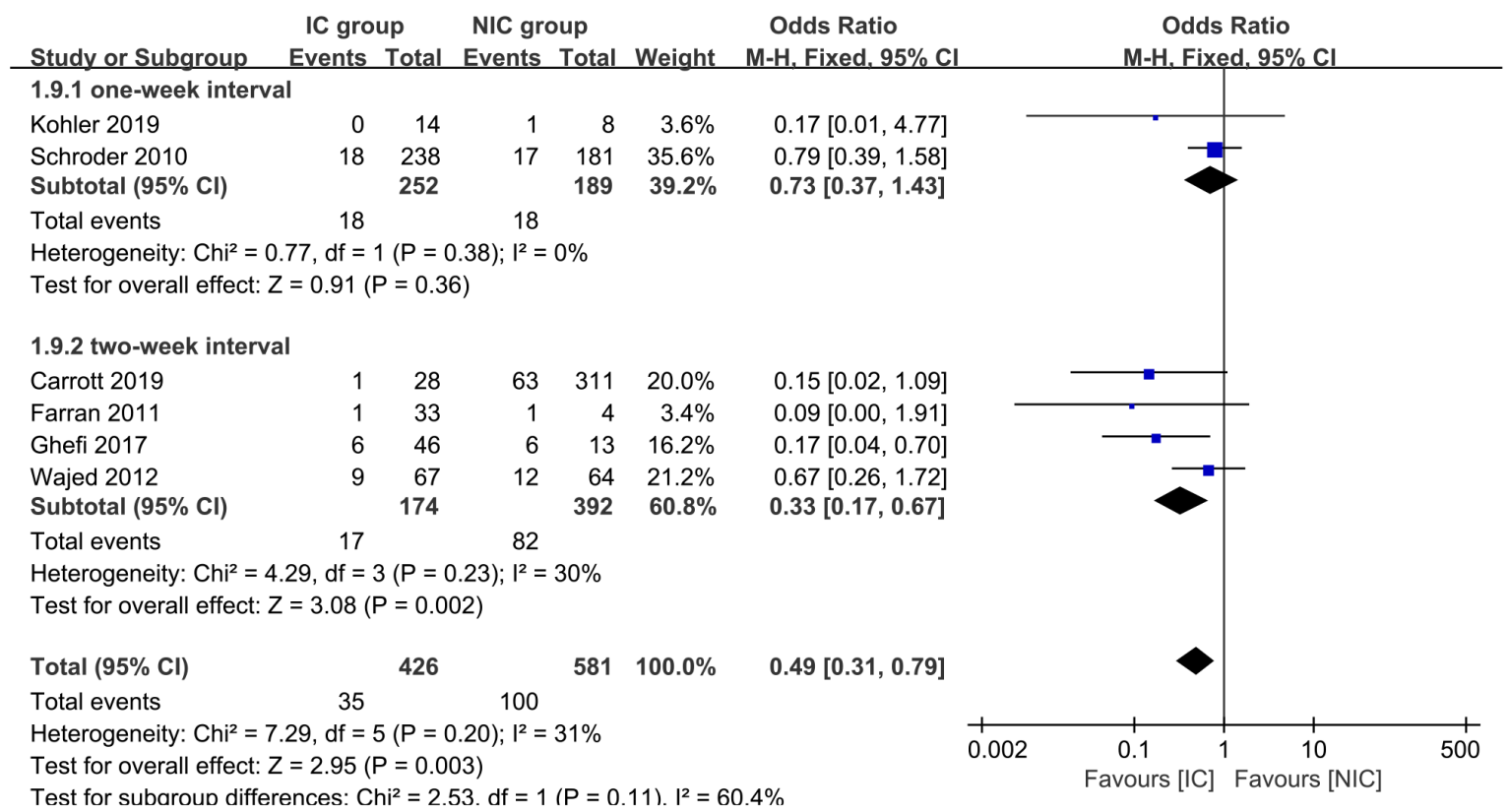

Figure 3 Subgroup analysis of the anastomotic leakage (AL) according to the interval between ischemic conditioning (IC) and gastroesophageal anastomosis. The IC was effective in the reducing of $\mathrm{AL}$ when the interval was above two weeks $(\mathrm{OR}=0.33,95 \% \mathrm{CI}$ : 0.17-0.67, $\mathrm{P}$ value $=0.002)$, while the incidence of $\mathrm{AL}$ was comparable between one-week interval IC and NIC group (OR =0.73, 95\% CI: $0.37-1.43, \mathrm{P}$ value $=0.36$ ).

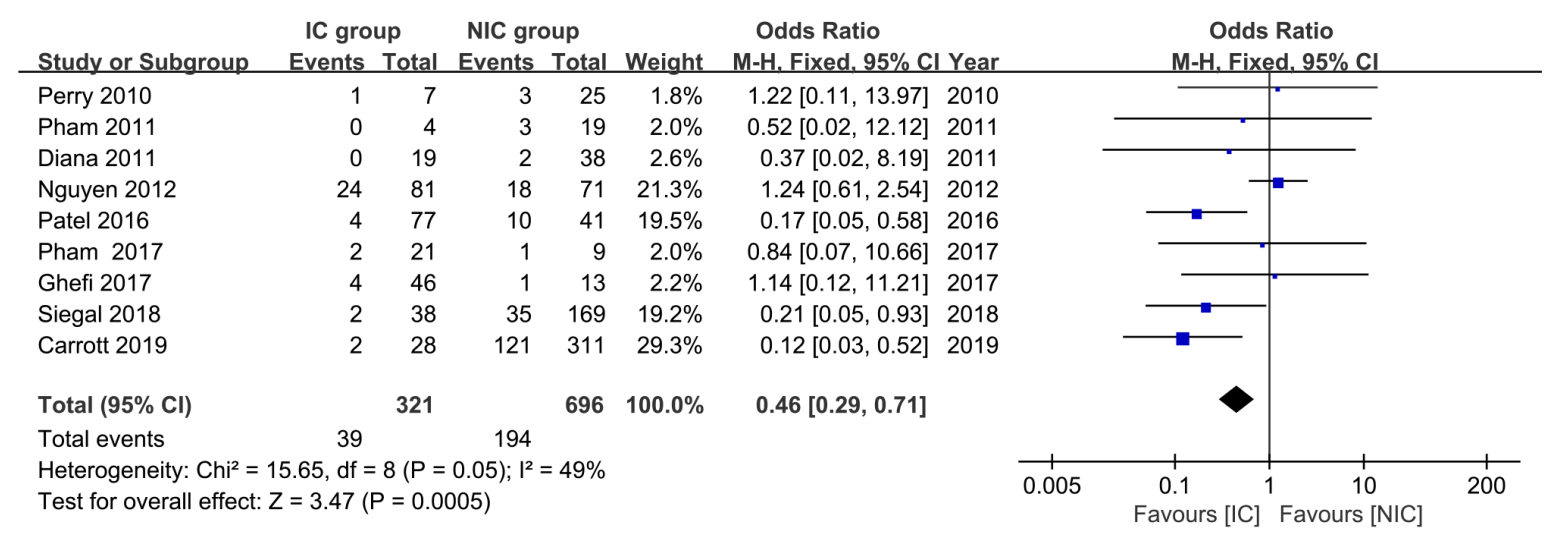

Figure 4 Comparison of anastomotic stricture rate between ischemic conditioning (IC) group and no ischemic conditioning (NIC) group. The IC group had a significantly lower stricture rate than the NIC group ( $12.1 \%$ vs. $27.9 \%$, OR $=0.46,95 \%$ CI: $0.29-0.71$, P value $=0.0005)$.

latter often happens a long time after the surgery, and it is much less dangerous. The AS is handled by endoscopic dilation mostly. As for AL, it often happened within a short time after the surgery. It is an unpredictable and lethal complication. The early reorganization of highrisk patients, well preoperative communication, early postoperative detection, and timely treatment are the rules for the management of AL. The good drainage and adequate nutrient supply are the major weapons to deal with the AL, and most patients could recover in a few weeks. However, about $5-10 \%$ of patients who suffer from AL would die (28). So the prevention of AL is quite important.

The previously published meta-analysis showed patients who underwent IC had a lower incidence of anastomotic 


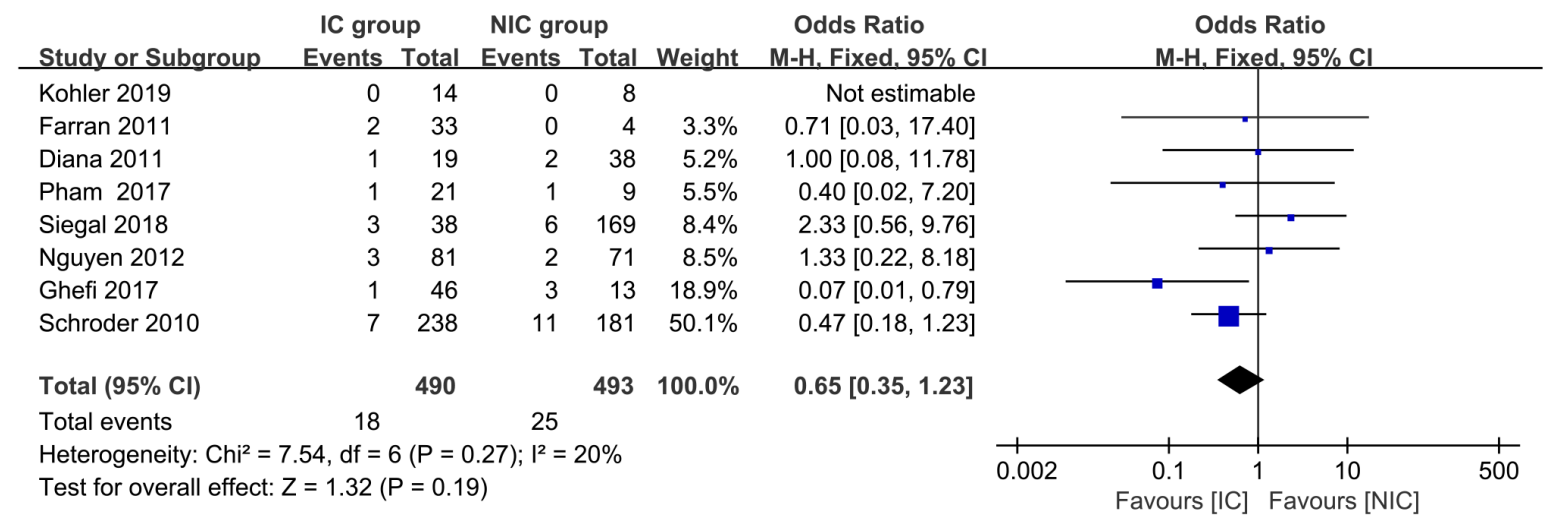

Figure 5 Comparison of mortality between ischemic conditioning (IC) group and no ischemic conditioning (NIC) group. The mortality was comparable between IC and NIC group [ $3.7 \%$ vs. $5.1 \%$, OR=0.65, 95\% CI: $0.35-1.23$ ), P value $=0.19]$.

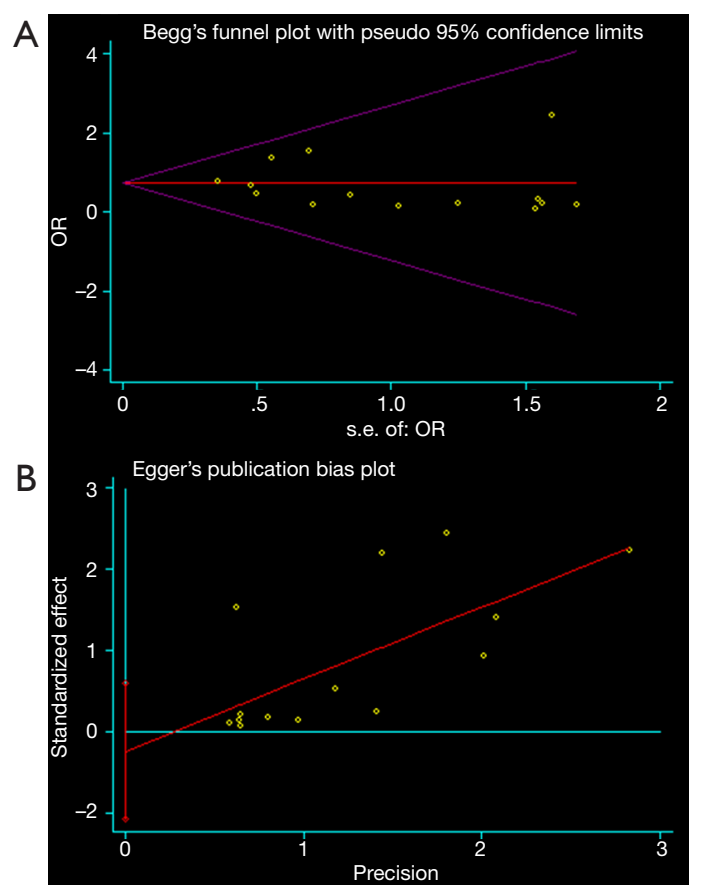

Figure 6 Begg's and Egger's test for the detection of publication bias. Both the Begg's ( $\mathrm{P}$ value $=0.913$ ) and Egger's test $(\mathrm{P}$ value $=0.544$ ) detected no publication bias in the comparison of anastomotic leakage.

complications than those who did not (14). However, the difference didn't reach a statistical significance. After the inclusion of newly published studies, our study proved the efficacy of the ischemic conditioning (IC) in the reduction of anastomotic complications for the first time. The IC significantly decreased the incidence of anastomotic leakage, and it also reduced the happen of postoperative stricture.

The blood supply around the gastric fundus is weaker than other parts of the stomach, so that the top portion of the gastric conduit is especially insufficient in blood supply (29). Therefore, the cervical anastomosis, which has to put the anastomotic site closer to the top of the conduit, has a significantly higher risk of anastomotic leakage (AL) than the intrathoracic anastomosis (4). So, the efficacy of the IC should be more dominant in patients undergoing cervical anastomosis theoretically. Among the fourteen studies included in the meta-analysis, two studies $(20,23)$ performed cervical anastomosis, and another two studies $(21,26)$ performed intrathoracic anastomosis. In contrast, the left ten studies perform both the cervical and intrathoracic anastomosis. So the subgroup analysis, according to the anastomotic level, was unable to be performed independently. If the patients undergoing cervical anastomosis would benefit more from the ischemic conditioning needs to be further proved.

The embolization or ligation of the gastric vessels may promote the hypertrophy and neovascularization of the preserved gastric vessels $(6,30)$. The compensation helps the stomach adapt to the decline of the blood supply gradually. It is how the ischemic conditioning works. The animal experiments conducted by Perry et al. showed the 7-day ischemic conditioning didn't produce increased neovascularity while the 30-day conditioning increased the microvessel counts significantly (13). So, the interval between the IC and esophagectomy is an essential factor affecting the efficacy of the IC. However, the optimal interval remains questionable, and it varies significantly among different studies $(6,23,31)$. The subgroup analysis, 
according to the interval between IC and anastomosis, showed the incidence of $\mathrm{AL}$ was comparable between the IC group and the NIC group in the 1-week subgroup. When it came to the 2-week subgroup, the IC group had a statistically significant lower rate of AL than the NIC group. Therefore, the interval between IC and surgery should be enough to let the compensations happen. The results of our analysis recommended the interval should be over 2 weeks.

The anastomotic stricture is a complication that dramatically decreases the quality of life of the patients $(32,33)$. The stricture rate could be as high as $18-42 \%$ after the gastroesophageal anastomosis (32). Siegal et al. reported the IC could significantly decrease the incidence of anastomotic stricture fourfold (5). The studies conducted by Carrott et al. and Patel et al. also supported the result $(25,27)$. Our meta-analysis showed the overall incidence of anastomotic stricture dropped to $12.1 \%$, which otherwise would be as high as $27.9 \%$. The animal experiment showed the IC could increase muscularis propria preservation and decreased collagen deposition at the healing anastomosis (13). So the low stricture rate in the IC group may associate with the reduced fibrosis of the anastomotic site.

The IC is a traumatic procedure. So it also has some side effects. The side effect of the laparoscopic approach is similar to general laparoscopic gastric surgery such as wound infection, bleeding, hiatal hernia, and so on (24). As for the embolization approach, it is more complicated. The reported side effect includes partial splenic infarct, vesicular ischemia, gastric perforation, and pancreatitis, and so on (18). Thankfully, the morbidity rate is quite low, and most of them are mild.

In summary, our study proved the ischemic conditioning is a safe intervention that could reduce the anastomotic complications effectively. It could play a role in the prevention of anastomotic leakage among high-risk patients. However, the studies included in the meta-analysis were cohort or case-control study. It brought down the evidence level of our findings. Future randomized controlled clinical trials are needed to provide high-level evidence on this topic.

\section{Acknowledgments}

We would like to thank Mr. Shi-De Wu from the High School Attached to Northeast Normal University for his linguistic assistance to this manuscript.
Funding: The National Natural Science Foundation of China supported the study (Grant number: 81672291, 31071210).

\section{Footnote}

Reporting Checklist: The authors have completed the PRISMA reporting checklist. Available at http://dx.doi. org/10.21037/apm-19-569

Peer Review File: Article information: http://dx.doi. org/10.21037/apm-19-569

Conflicts of Interest: All authors have completed the ICMJE uniform disclosure form (available at http://dx.doi. org/10.21037/apm-19-569). The authors have no conflicts of interest to declare.

Ethical Statement: The authors are accountable for all aspects of the work in ensuring that questions related to the accuracy or integrity of any part of the work are appropriately investigated and resolved. This is a metaanalysis. It does not involve any ethical or informed consent problems. This article does not contain any studies with human participants performed by any of the authors.

Open Access Statement: This is an Open Access article distributed in accordance with the Creative Commons Attribution-NonCommercial-NoDerivs 4.0 International License (CC BY-NC-ND 4.0), which permits the noncommercial replication and distribution of the article with the strict proviso that no changes or edits are made and the original work is properly cited (including links to both the formal publication through the relevant DOI and the license). See: https://creativecommons.org/licenses/by-nc-nd/4.0/.

\section{References}

1. Ajani JA, D'Amico TA, Bentrem DJ, et al. Esophageal and Esophagogastric Junction Cancers, Version 2.2019, NCCN Clinical Practice Guidelines in Oncology. J Natl Compr Canc Netw 2019;17:855-83.

2. Sakamoto T, Fujiogi M, Matsui H, et al. Comparing Perioperative Mortality and Morbidity of Minimally Invasive Esophagectomy Versus Open Esophagectomy for Esophageal Cancer: A Nationwide Retrospective Analysis. Ann Surg 2019. [Epub ahead of print].

3. Goense L, van Rossum PS, Tromp M, et al. Intraoperative 
and postoperative risk factors for anastomotic leakage and pneumonia after esophagectomy for cancer. Dis Esophagus 2017;30:1-10.

4. Gooszen JAH, Goense L, Gisbertz SS, et al. Intrathoracic versus cervical anastomosis and predictors of anastomotic leakage after oesophagectomy for cancer. Br J Surg 2018;105:552-60.

5. Siegal SR, Parmar AD, Haisley KR, et al. Gastric Ischemic Conditioning Prior to Esophagectomy Is Associated with Decreased Stricture Rate and Overall Anastomotic Complications. J Gastrointest Surg 2018;22:1501-07.

6. Prudius V, Prochazka V, Pavlovsky Z, et al.

Neovascularization after ischemic conditioning of the stomach and the influence of follow-up neoadjuvant chemotherapy thereon. Wideochirurgia I Inne Techniki Maloinwazyjne 2018;13:299-305.

7. Deng J, Su Q, Ren Z, et al. Comparison of short-term outcomes between minimally invasive McKeown and Ivor Lewis esophagectomy for esophageal or junctional cancer: a systematic review and meta-analysis. Onco Targets Ther 2018;11:6057-69.

8. van Workum F, Berkelmans GH, Klarenbeek BR, et al. McKeown or Ivor Lewis totally minimally invasive esophagectomy for cancer of the esophagus and gastroesophageal junction: systematic review and metaanalysis. J Thorac Dis 2017;9:S826-33.

9. Ohi M, Saigusa S, Toiyama Y, et al. Evaluation of Blood Flow with Indocyanine Green-Guided Imaging to Determine Optimal Site for Gastric Conduit Anastomosis to Prevent Anastomotic Leak after Esophagectomy. Am Surg 2017;83:e197-9.

10. Ladak F, Dang JT, Switzer N, et al. Indocyanine green for the prevention of anastomotic leaks following esophagectomy: a meta-analysis. Surg Endosc 2019;33:384-94.

11. Turner SR, Molena DR. The Role of Intraoperative Fluorescence Imaging During Esophagectomy. Thorac Surg Clin 2018;28:567-71.

12. Pham TH, Melton SD, McLaren PJ, et al. Laparoscopic ischemic conditioning of the stomach increases neovascularization of the gastric conduit in patients undergoing esophagectomy for cancer. J Surg Oncol 2017;116:391-97.

13. Perry KA, Banarjee A, Liu J, et al. Gastric ischemic conditioning increases neovascularization and reduces inflammation and fibrosis during gastroesophageal anastomotic healing. Surg Endosc 2013;27:753-60.

14. Heger P, Blank S, Diener MK, et al. Gastric
Preconditioning in Advance of Esophageal ResectionSystematic Review and Meta-Analysis. J Gastrointest Surg 2017;21:1523-32.

15. Slim K, Nini E, Forestier D, et al. Methodological index for non-randomized studies (minors): development and validation of a new instrument. ANZ J Surg 2003;73:712-6.

16. Akiyama S, Kodera Y, Sekiguchi H, et al. Preoperative embolization therapy for esophageal operation. J Surg Oncol 1998;69:219-23.

17. Diana M, Hubner M, Vuilleumier H, et al. Redistribution of gastric blood flow by embolization of gastric arteries before esophagectomy. Ann Thorac Surg 2011;91:1546-51.

18. Ghelfi J, Brichon PY, Frandon J, et al. Ischemic Gastric Conditioning by Preoperative Arterial Embolization Before Oncologic Esophagectomy: A Single-Center Experience. Cardiovasc Intervent Radiol 2017;40:712-20.

19. Farran L, Miro M, Alba E, et al. Preoperative gastric conditioning in cervical gastroplasty. Dis Esophagus 2011;24:205-10.

20. Perry KA, Enestvedt CK, Pham TH, et al. Esophageal replacement following gastric devascularization is safe, feasible, and may decrease anastomotic complications. J Gastrointest Surg 2010;14:1069-73.

21. Schröder W, Holscher AH, Bludau M, et al. IvorLewis Esophagectomy With and Without Laparoscopic Conditioning of the Gastric Conduit. World J Surg 2010;34:738-43.

22. Pham TH, Perry KA, Enestvedt CK, et al. Decreased conduit perfusion measured by spectroscopy is associated with anastomotic complications. Ann Thorac Surg 2011;91:380-85.

23. Wajed SA, Veeramootoo D, Shore AC. Surgical optimisation of the gastric conduit for minimally invasive oesophagectomy. Surg Endosc 2012;26:271-6.

24. Nguyen NT, Nguyen X-MT, Reavis KM,et al. Minimally invasive esophagectomy with and without gastric ischemic conditioning. Surg Endosc 2012;26:1637-41.

25. Patel LY, Ganai S, Johnson B, et al. Clinical outcomes following esophagectomy with and without laparoscopic ischemic gastric pre-conditioning. Gastroenterology 2016;150:S1181-2.

26. Köhler H, Jansen-Winkeln B, Maktabi M, et al. Evaluation of hyperspectral imaging (HSI) for the measurement of ischemic conditioning effects of the gastric conduit during esophagectomy. Surg Endosc 2019;33:3775-82.

27. Carrott PW, Miller J, Chang A, et al. Gastric Ischemic 
Conditioning before Esophagectomy: Timing and Method Matter. J Am Coll Surg 2019;229:e207-8.

28. Fumagalli U, Baiocchi GL, Celotti A, et al. Incidence and treatment of mediastinal leakage after esophagectomy: Insights from the multicenter study on mediastinal leaks. World J Gastroenterol 2019;25:356-66.

29. Ortega CB, Guerron AD, Yoo JS. The Use of Fluorescence Angiography During Laparoscopic Sleeve Gastrectomy. JSLS 2018;22:e2018.00005.

30. Strosberg DS, Merritt RE, Perry KA. Preventing anastomotic complications: early results of laparoscopic gastric devascularization two weeks prior to minimally invasive esophagectomy. Surg Endosc 2017;31:1371-75.

Cite this article as: Zhuo ZG, Shen $\mathrm{X}$, Song TN, Xu ZJ, Alai GH, Yao P, Lin YD. The efficacy of ischemic conditioning in the prevention of gastroesophageal anastomotic complications: a meta-analysis. Ann Palliat Med 2020;9(4):15861595. doi: 10.21037/apm-19-569
31. Prochazka V, Marek F, Kunovsky L, et al. Comparison of cervical anastomotic leak and stenosis after oesophagectomy for carcinoma according to the interval of the stomach ischaemic conditioning. Ann R Coll Surg Engl 2018;100:509-14.

32. Nishikawa K, Fujita T, Yuda M, et al. Early prediction of complex benign anastomotic stricture after esophagectomy using early postoperative endoscopic findings. Surg Endosc 2020;34:3460-9.

33. Ahmed Z, Elliott JA, King S, et al. Risk Factors for Anastomotic Stricture Post-esophagectomy with a Standardized Sutured Anastomosis. World J Surg 2017;41:487-97. 